\title{
Tumor necrosis factor receptor-associated factors (TRAFs)-a family of adapter proteins that regulates life and death
}

\author{
Robert H. Arch, ${ }^{1-3}$ Richard W. Gedrich, ${ }^{1,3,4}$ and Craig B. Thompson ${ }^{1-3,5}$ \\ ${ }^{1}$ Gwen Knapp Center for Lupus and Immunology Research and ${ }^{2} \mathrm{H}$ oward Hughes Medical Institute, ${ }^{3}$ Department \\ of Medicine, The University of Chicago, Chicago, Illinois 60637 USA
}

The signaling pathways that regulate cell survival are beginning to be defined. Receptors such as Fas and tumor necrosis factor receptor type I (TN FRI) have been shown to be capable of initiating programmed cell death. These death receptors initiate signal transduction pathways that culminate in caspase activation and apoptosis. A number of the intracellular molecules in these signaling pathways have been identified and characterized. In contrast to death receptors, other cell surface receptors appear to be capable of initiating signaling pathways that promote cell survival. The components of survival signal transduction are less well characterized. Recently a family of cytoplasmic proteins has been identified that appears to be capable of both negatively regulating apoptotic pathway(s) as well as inducing the expression of genes that promote cell survival. Members of this family of signal transduction molecules were first described because of their ability to bind to TNFRII and, therefore, were given the name TNF receptor-associated factors (TRAFs). Subsequent studies have demonstrated that TRAFs serve as adapter proteins for a wide variety of cell surface receptors and play important roles in regulating not only apoptosis but also stress responses. In this review we hope to provide an overview of current knowledge concerning the expression and function of this important family of proteins.

\section{Identification of the TRAF family}

Members of the recently described family of TRAF proteins are cytoplasmic adapter proteins that can interact directly with the intracellular domains of cell surface receptors. Among the receptors that have been shown to recruit TRAF proteins are members of the TNFR superfamily, the Epstein-Barr virus protein LMP1, and the interl eukin-1 receptor (IL-1R). To date, six distinct TRAF molecules have been identified in mammalian species (Fig. 1). TRAF1 and TRAF2 were cloned by biochemical

\footnotetext{
${ }^{4}$ Present address: Bayer Corporation, West Haven, Connecticut 06516 USA.

${ }^{5}$ Corresponding author.

E-MAIL craig@knapp.uchicago.edu; FAX (773) 702-1576.
}

characterization of intracellular factors that associated with TNFRII (Rothe et al. 1994). TRAF3 (LAP-1, CD40bp, CRAF-1) was described independently as a cytoplasmic factor that interacts with CD40 and LMP-1 (Hu et al. 1994; Cheng et al. 1995; Mosial os et al. 1995; Sato et al. 1995). TRAF4 (CART1, C-rich motif associated with RING and TRAF domains 1 ) was isolated by differential screening of a CDN A library of Iymph nodes that contained metastatic tumor cells (Régnier et al. 1995). TRAF5 was identified by utilization of degenerate PCR primers that were homologous to a highly conserved region at the carboxy-terminal end of TRAF proteins (TRAF-C domain) and independently in a yeast two-hybrid screen (Ishida et al. 1996a; Nakano et al. 1996). TRAF6 was isolated independently by the screening of an EST expression library and by utilizing CD 40 as bait for a yeast two-hybrid screen (Cao et al. 1996; Ishida et al. 1996b).

\section{Predicted structural domains of TRAF proteins}

All TRAFs share a common stretch of amino acids at their carboxyl terminus (C ao et al. 1996). This TRAF domain has been shown to be required for the binding of TRAF proteins to their associated receptors. The TRAF domain has been divided into two subregions (Rothe et al. 1994). The carboxy-terminal TRAF-C region of high amino acid homology has been shown to mediate both homo- and heterodimerization of TRAF proteins and interactions of the adapter proteins with distinct cell surface receptors that are capable of recruiting TRAFs (see Tables 1 and 2) (Cheng et al. 1995; Hsu et al. 1996; Takeuchi et al. 1996). The amino-terminal half of the TRAF domain, TRAF-N, is predicted to adopt a coiledcoil configuration.

TRAF proteins share a number of additional predicted structural features. With the exception of TRAF1, all TRAFs contain an amino-terminal RING finger domain. RING fingers have a characteristic pattern of cysteines and histidines that are capable of coordinating the binding of $\mathrm{Zn}^{2+}$ ions (Borden et al. 1995). Similar domains are described in a variety of other proteins, such as RAG (recombination activating gene) 1 and RAG2, BRCA-1 
Arch et al.

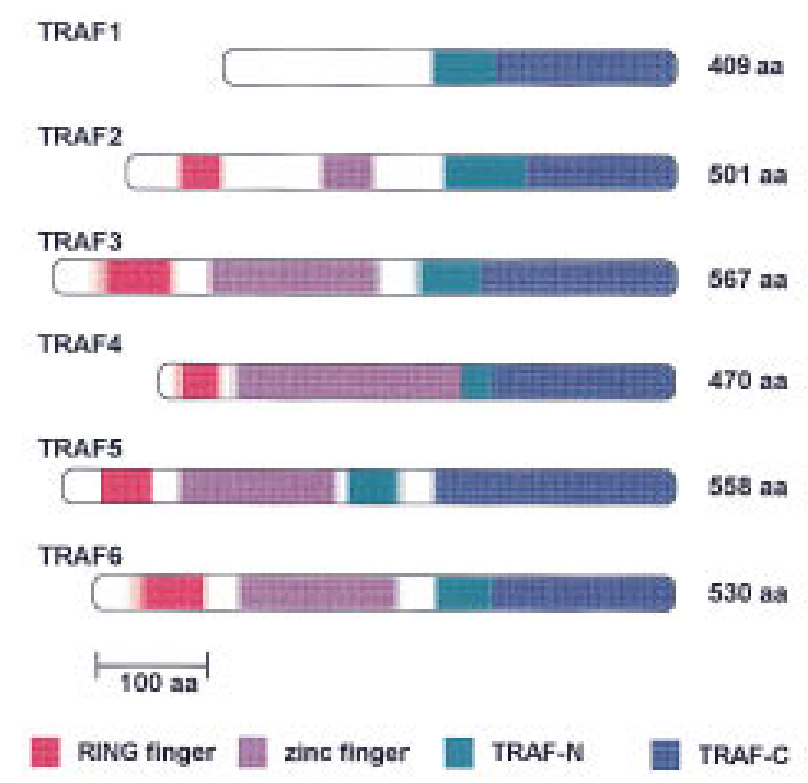

Figure 1. Structure of the known TRAF proteins. Shown is the number of amino acids (right) of murine TRAF proteins. Colored boxes represent the relative positions of described protein domains as indicated.

(breast cancer susceptibility gene product 1 ), PML (promyelocytic leukemia), RING1, and the yeast protein Ste-5 (Borden and Freemont 1996; Bellon et al. 1997; Inouye et al. 1997). Whereas the deletion of the aminoterminal RING domain of TRAF proteins leads to the generation of dominant-negative TRAF mutants, interactions mediated by this domain with other macromolecules have not been shown (Rothe et al. 1995b). Re cently, a splice variant of TRAF2 has been characterized that contains an insert of seven amino acids in the RIN G finger structure that results in a natural dominant-negative TRAF2 molecule (Brink and Lodish 1998). Downstream of the RING-finger domain, TRAFs, with the exception of TRAF1, contain a stretch of predicted zinc fingers. Zinc finger domains of other proteins have been shown to mediate DNA binding and/or protein-protein interactions (M ackay and Crossley 1998).

The structural features of TRAF proteins suggest that these proteins function as cytoplasmic adapters, which may promote intracellular signal transduction through their ability to bind to receptors and potentiate the recruitment of proteins, including each other, to a signaling complex. Consistent with this, TRAF1, TRAF2, TRAF3, TRAF5, and TRAF6 are local ized in the soluble fraction of the cytoplasm of cells. Furthermore, at least TRAF2 and TRAF3 could be shown to redistribute to the cell surface upon receptor oligomerization (Kuhné et al. 1997). Only one TRAF protein seems to have a distinct pattern of subcellul ar localization. TRAF4 appears to be a predominantly nuclear protein (Régnier et al. 1995; J.L. Van Dongen and C. Thompson, unpubl.). In addition, TRAF4 remains the sole mammalian TRAF not characterized by the ability to bind to a known cell surface receptor.
Table 1. Interactions between TRAF proteins and cell surface receptors

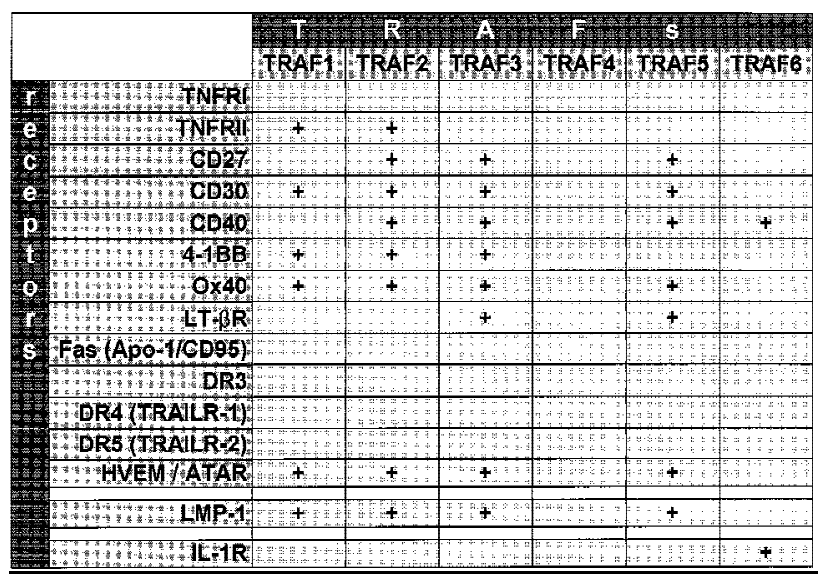

Summarized is the current knowledge of interactions between cell surface receptors and TRAFs (see text for details).

\section{Tissue distribution of TRAF proteins}

Although TRAF2, TRAF3, and TRAF6 are expressed ubiquitously, the expression patterns of TRAF1, TRAF4, and TRAF5 are more restricted (Rothe et al. 1994; Mosialos et al. 1995; Régnier et al. 1995; Cao et al. 1996; Ishida et al. 1996a,b; Nakano et al. 1996). The highest expression levels of TRAF1 can be found in spleen, lung, and testis, whereas TRAF5 is highly expressed in spleen, lung, and thymus. TRAF4 is highly expressed during embryogenesis and in the adult hippocampus and olfactory bul b but was not detected in other normal tissues. High expression levels of TRAF4 can al so be found in a variety of breast carcinoma cell lines (M asson et al. 1998).

\section{TRAFs can be recruited to distinct cell surface receptors}

TRAF molecules have been shown to interact with the cytoplasmic domains of distinct members of the TN FR superfamily and other cell surface proteins (T able 1). The TRAF-C domain mediates the interactions between TRAF proteins and the receptor tails. A number of studies have attempted to define the TRAF binding site(s) of these receptors. CD 40, CD 30, CD27, and LM P1 contain a PXQX(T/S) motif that has been demonstrated to mediate the interactions with TRAFs (Devergne et al. 1996; Gedrich et al. 1996; Aizawa et al. 1997; Boucher et al.

Table 2. Homo- and heterodimerization of TRAF proteins

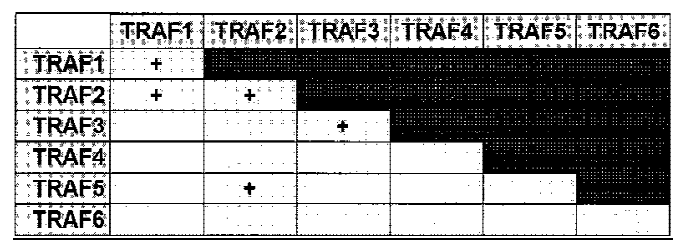

TRAF proteins have been shown to form homo- and/or heterodimers that are mediated by their TRAF-C domain (see text for details). 
1997; Brodeur et al. 1997; Sandberg et al. 1997; A ki ba et al. 1998). In other receptors, TRAF binding sites have been localized to stretches of 5-7 acidic amino acids (Gedrich et al. 1996; Arch and Thompson 1998). TRAF2, TRAF3, and TRAF5 have been shown to bind to overlapping subsets of receptors, apparently by competition for the same binding sites (see Table 1) (Gedrich et al . 1996; Lee et al. 1996a; A izawa et al. 1997; Boucher et al. 1997; Arch and Thompson 1998). In contrast, TRAF6 interacts with only one TN FR family member, CD40, and this site is distinct from the binding site for TRAF2, TRAF3, and TRAF5 (Ishida et al. 1996b). TRAF6 al so links the TRAF signaling transduction cascade to another intracellular signaling pathway triggered by the IL-1R after binding to its cytokine ligand (Cao et al. 1996). Recently, a dominant-negative form of TRAF6 has been shown to inhibit signal transduction through the mammalian homolog of Toll, a key regulator of innate immunity in both vertebrates and invertebrates (M edzhitov et al. 1997, 1998).

\section{The role of TRAFs in the activation of stress responses}

Recruitment of TRAF adapter proteins to the cytoplasmic domains of receptor molecules can lead to the assembly of larger signaling compl exes that consist of distinct TRAF adapter molecules and other effector proteins with enzymatic functions. N umerous reports have examined the activation of intracellular kinases in response to TRAF-dependent signal transduction. In particular, kinases of the mitogen-activated protein kinase (MAPK) family have been shown to be key players for signaling pathways that are triggered by TRAF-containing complexes. These pathways appear to culminate in c-Jun amino(N)-terminal kinase (JNK) activation (Reinhard et al. 1997; Song et al. 1997). TRAF proteins thus can serve to modulate the ability of receptors to trigger distinct signaling pathways that lead to phosphorylation and activation of protein kinases and, subsequently, to the activation of transcription factors of the Rel and AP-1 family.

The c-Jun transcription factor is phosphorylated at its amino terminus by JNK, the most downstream member of one MAPK signaling pathway (Hibi et al. 1993). To be activated JNK needs to be phosphorylated by a MAPK kinase (MAPKK, SEK, MEK). This kinase itself is phosphorylated by a MAPKKK (MEKK1), which can be activated through phosphorylation by GCKR (germinal center kinase related) protein, the most upstream kinase described in this pathway (Minden et al. 1994; Lin et al. 1995; Shi and Kehrl 1997). Dominant-negative mutants of either of these proteins that lack kinase activity block TRAF-mediated JN K activation that is induced by members of the TNFR superfamily. Thus, TRAF proteins appear to regulate the JNK activation pathway at a very proximal step (Liu et al. 1996; Lee et al . 1997a; Reinhard et al. 1997). Cells from TRAF2-deficient mice failed to activate JN K in response to TN F- $\alpha$ (Y eh et al. 1997). JN K has been demonstrated to mediate the integration of a costimulatory signal by CD28 during activation of $T$ Iymphocytes (Su et al. 1994). Taken together, these re- sults suggest that costimulation by CD28 and TRAFmediated costimulation after ligation of TNFR-related molecules utilize the same distal signaling components.

TRAF proteins also appear to play an important role in modulating an early step in receptor-induced activation of N F-kB (Rothe et al. 1995b; Cao et al. 1996; N akano et al. 1996). NF-кB is a family of heterodimeric transcription factors that are located in the cytoplasm as inactive heterotrimeric precursor complexes (Baldwin 1996; Verma and Stevenson 1997). U pon phosphorylation by specific IкB kinases (IKK $\alpha$ and IKK $\beta$ ) the inhibitor protein $I_{\kappa} B$ becomes ubiquitinated and degraded by proteasome complexes (DiDonato et al. 1997; Régnier et al. 1997; Zandi et al. 1997). The dissociati on of I $\mathrm{k}$ from the inactive heterotrimeric complex leads to activation of transcriptionally active N F-кB heterodimers that translocate to the nucleus and bind specific NF- $\mathrm{B}$ binding sites in the promoters of N F-kB-responsive genes. IKKs can be phosphorylated by the MAPK NIK (NF-кB-inducing kinase). N IK has recently been shown to be part of $a$ signaling compl ex that is assembled by the multimerization of TRAF proteins upon recruitment to cell surface receptors (Malinin et al. 1997; Song et al. 1997). Evidence that TRAF proteins can influence receptor-mediated activation of $N F-\kappa B$ came from the demonstration that dominant-negative forms of TRAF2 can inhibit NF-кB activation in response to oligomerization of several TNFR-related molecules, including TNFRII, CD40, CD30, 4-1BB, and Ox40 (Rothe et al. 1994, 1995b; Duckett et al. 1997; Arch and Thompson 1998). However, gene el imination studies in mi ce have failed to implicate a required role for a specific TRAF in N F- $\mathrm{B}$ B activation by any of these receptors (Lee et al. 1997a; Y eh et al. 1997). This suggests that receptor engagement may activate N F-кB by more than one pathway.

\section{TRAF-interacting intracel lular proteins}

Receptor multimerization recruits members of the TRAF family and/or other intracellular proteins to the cytoplasmic domains of the receptor and leads to the assembly of multiprotein signaling complexes. Recent work has suggested that TNFR-related proteins can be divided into at least two distinct subfamilies, both of which can induce signaling complexes that include TRAF proteins. One subfamily is defined by the presence of a so-called death domain in the cytoplasmic tail (Huang et al. 1996). Multimerization of death domain containing receptors leads to the recruitment of intracellular adapter proteins that also contain death domainhomology regions. For example, TNFRI interacts with the adapter molecule TRADD (TN F $\underline{R}$-associated death domain protein) and Fas (A po-1, CD95) recruits FADD / M ORT-1 (Fas-associated death domain protein, mediator of receptor-induced toxicity $\underline{1}$ ) (Chinnaiyan et al. 1995; Hsu et al. 1995). Both TRADD and FADD have been shown directly or indirectly to interact with members of the TRAF family and, therefore, initiate TRAF-mediated signaling processes (Hsu et al. 1996; Liu et al. 1996).

Many TNFR family members appear to lack intracel- 
Iular death domains. Each of these receptors appears to share the ability to bind TRAF proteins. Where it has been studied, the TRAF binding site(s) of these receptors appear(s) to be required for signal transduction by these receptors. The signaling cascades that are initiated by receptor recruitment of either TRAF molecules or death domain containing adapter proteins are regulated by proteins that can interfere with specific steps by modifying the composition of the multiprotein complexes and/or by blocking protein-protein interactions and downstream effector functions (Fig. 2). Among these modifying proteins are other adapter proteins like A20, c-IAPs (cellular inhibitor of apoptosis), TRIP (TRAF-interacting protein), and I-TRAF/TANK (TRAF-interacting protein, TRAF family member-associated NF-кB activator) (Rothe et al. 1995a, 1996; Cheng and Baltimore 1996; Lee et al. 1997b; Roy et al. 1997). Each of these proteins has been shown to be capable of interactions with members of the TRAF family (Table 3). Y et, the functional roles of these interactions have been demonstrated to be quite distinct. A20 expression levels are up-regulated by the induction of NF-kB, and increased levels of A20 lead to an inhibition of TRAF2-mediated N F-kB induction (Song et al. 1996). Despite this negatively regulating effect on
Table 3. Interactions between TRAF proteins and intracellular proteins

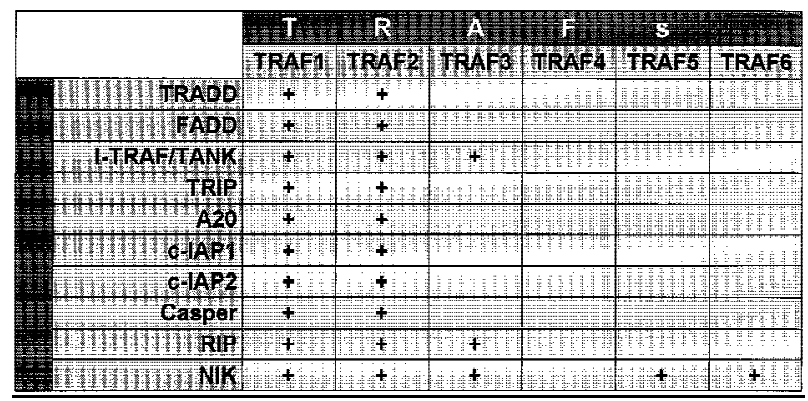

Summarized are intracellular proteins that have been shown to interact with TRAF molecules (see text for details).

N F-кB induction, A20 has been demonstrated to diminish programmed cell death (Opipari et al. 1992). TRIP and I-TRAF/TANK are thought to modul ate the effector functions of TRAFs directly. Although TRIP was shown to block NF-kB activation mediated by TRAF proteins, I-TRAF/TANK seems to augment or block N F-kB activation dependent on the cellular context (Cheng and Baltimore 1996; Rothe et al. 1996; Lee et al. 1997b). Two

Figure 2. TRAF proteins can be recruited by multimerized cell surface receptors. Interactions between TRAFs and other proteins in multiprotein complexes regulate downstream signaling cascades and determine the fate of a cell. Possible interactions of TRAF proteins oligomerized with cell surface receptors (green and red) and the adapter proteins TRADD and FADD are symbolized by arrows. The roles of I-TRAF/ TANK and TRIP are also indicated. In contrast to TRAF1, TRAF2, TRAF3, TRAF5, and TRAF6, TRAF4 has been shown to be localized in the nucleus. One possible explanation for this subcellular localization is a regulatory and/or effector function of TRAF4 in gene transcription. To date, no such function could be shown and it is also not clear if putative TRAF4 target genes have a role in cell survival. Because of limited space, the figure cannot give a complete summary of downstream molecules and effector functions in the diagram, but, rather, a simplified overview of proteins and pathways that are involved in the regulation of apoptosis is shown.

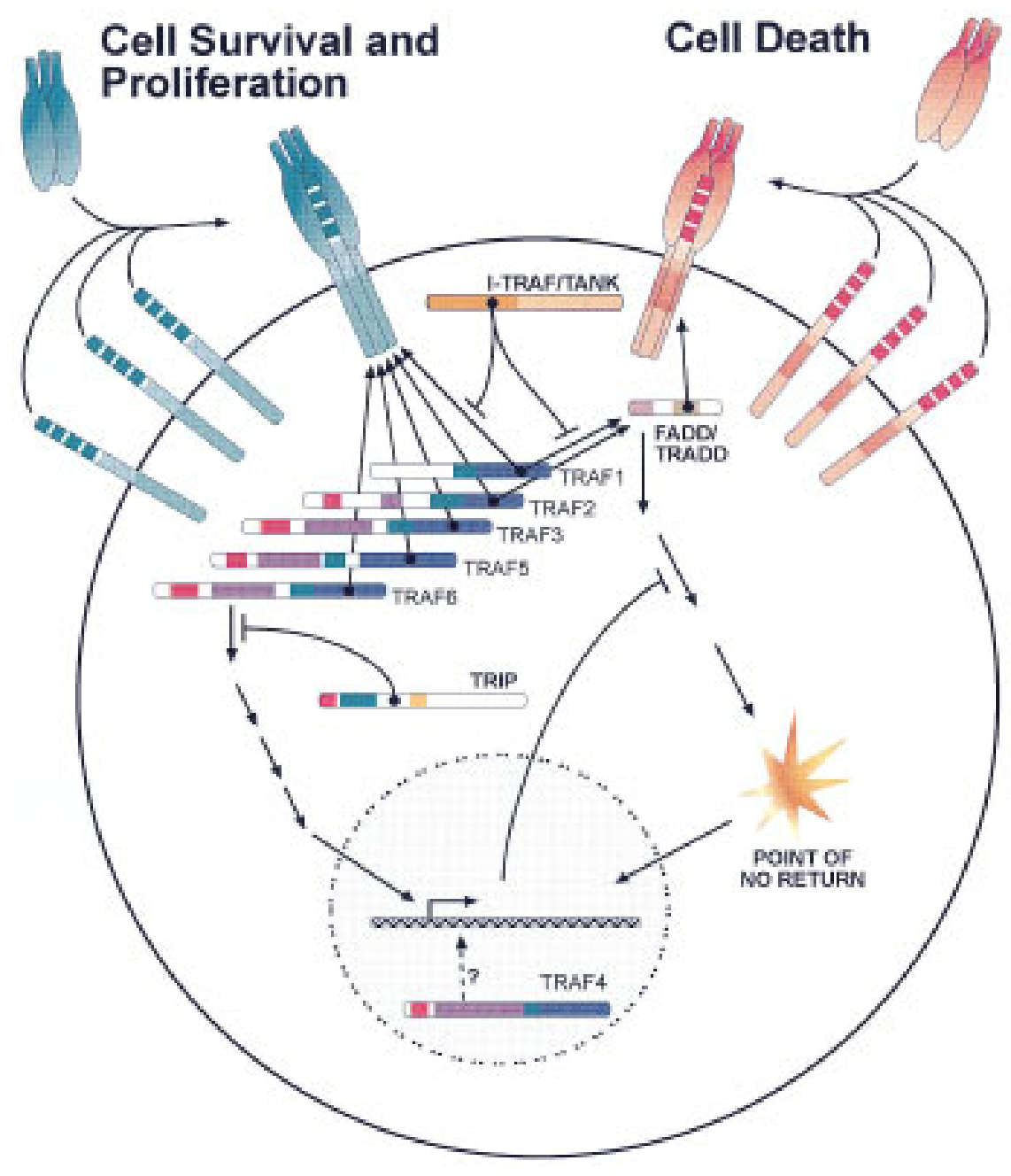


additional molecules that interact with TRAF2 are cIAP1 and c-IAP2 (Rothe et al. 1995a; Uren et al. 1996). Both have been shown to interfere with the activation of caspases by cytochrome $c$ and, furthermore, can directly inhibit caspases 3 and 7 (Roy et al . 1997). These proteins may be an important link in the ability of TRAF-dependent signal transduction to modulate cell survival.

\section{TRAF-binding receptors can promote survival or initiate programmed cell death}

One important role of the TN FR superfamily is to regulate cell survival (Smith et al. 1994; Baker and Reddy 1996). Receptors that contain a so-called death domain in their cytoplasmic tail, for example, TNFRI, CD95, DR3, and TRAMP, in some instances can initiate complex cascades of proteases and kinases that lead to apoptosis (Itoh et al. 1991; Tartaglia et al. 1993; Clement and Stamenkovic 1994; Cleveland and Ihle 1995; Stanger et al. 1995; Chinnaiyan et al. 1996; Muzio et al. 1996; Ting et al. 1996; Huang et al. 1997; Saitoh et al. 1998). However, signal transduction through these receptors in other instances can also lead to activation of JNK and N F-кB, which has been shown to be crucial for lymphocyte activation and the induction of Iymphocyte effector functions (Su et al. 1994; Chinnai yan et al. 1996; Bodmer et al. 1997). In contrast, the induction of apoptosis by interactions between CD95 and its ligand has been shown to play a critical role in the induction of peripheral tolerance (Griffith et al . 1996; Van Parijs et al. 1996). The fate of a cell appears to be determined by the composition of the intracellular multiprotein aggregates that are formed after multimerizati on of the receptors (Huang et al. 1997; N agata 1997). The recruitment of functional FADD protein to death domain containing TN FR-related receptors leads to the induction of cell death, and a dominant-negative deletion mutant of this adapter protein that blocks apoptosis does not interfere with the activation of JNK or NF-kB (Hsu et al. 1996). In contrast, TRAF2 augments TNF- $\alpha$-induced JNK and NF-KB activation, and a dominant-negative mutant of TRAF2 blocks both downstream effects and enhances apoptosis (Lee et al. 1997a; Reinhard et al. 1997). Although the inhibition of NF-kB activation leads to an increase in programmed cell death, inhibition of JNK by dominantnegative MEKK1 diminishes the induction of apoptosis in HeLa cells but has a less pronounced effect in MCF7 cells (Beg and Baltimore 1996; Liu et al. 1996; Van Antwerp et al. 1996; Wang et al. 1996).

The death domain containing serine/threonine kinase RIP has also been shown to bind to a subset of TRAF proteins and can be recruited to TRAF-dependent signal ing compl exes. RIP is a member of a growing kinase family that plays a pivotal role in receptor-induced signal transduction (Stanger et al. 1995; M cCarthy et al. 1998). $\mathrm{RIP}^{-1-}$ cells fail to activate N F- $\mathrm{B}$ in response to TN F- $\alpha$, demonstrating a role for RIP in TNF- $\alpha$-induced NF-кB activation (Kelliher et al. 1998). Although the carboxyterminal death domain of RIP is necessary for the augmentation of cell death by RIP, deletion of the amino terminus that contains the kinase domain of RIP diminishes JN K activation. The domain in between the kinase domain and the death domain of RIP has been demonstrated to be necessary for the augmentation of NF-кB activation by RIP (Ting et al. 1996). These data suggest that death domain containing receptors can promote either a stress response or cell death, dependent on the composition of the adapter molecules recruited to the receptor.

A similar dichotomy exists for the outcome of signal transduction through TNFR-related molecules that directly recruit TRAF proteins. Both CD 30 and CD 40 have been shown to promote programmed cell death under certain circumstances, even though no death domain can be found in their cytoplasmic tails. T-cell lines stably transfected with CD8/CD30 chimeras undergo Fas-independent apoptosis after treatment with a combination of anti-T CR and anti-CD 8 anti bodies (Lee et al. 1996b). The induction of programmed cell death by CD30 is dependent on the carboxyl terminus of CD30 that contains the TRAF binding domain of the receptor. Whether this death is dependent on the ability of TRAF proteins to bind and recruit death domain containing proteins to the CD30 signaling complex has not yet been determined. Interestingly, the expression levels of TRAF1 were upregulated in T-cell hybridomas after cross-linking of the TCR, whereas TRAF2 expressi on was not al tered. In contrast, overexpression of TRAF1 in transgenic animals demonstrates an inhibitory role of TRAF1 on antigeninduced apoptosi s of CD8 ${ }^{+}$cells (Speiser et al . 1997). Like other members of the TRAF family, TRAF1 can be recruited to a variety of distinct members of the TNFR family. The results in TRAF1 transgenic animals argue for a role of TRAF1 in signaling pathways induced by other surface receptors than CD30. Thus, there appears to be a network of signaling pathways that utilize TRAF1 in distinct ways, dependent on the cellular context and regulated by expression level of TRAFs, cell surface receptors, and their ligands.

Targeted disruption of CD40 or its ligand CD40L results in viable mice that have defects in cellular and humoral immune responses, such as immunoglobulin class switching, germinal center formation, and cell-mediated immunity (Noelle 1996). Studies with CD40-1-

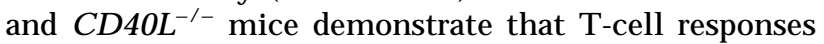
are polarized toward $T$ hel per2-type responses in the absence of CD 40 si gnaling (Kamanaka et al . 1996; Soong et al. 1996). CD 40 not only has been shown to interact with TRAF2, TRAF3, TRAF5, and TRAF6, but it also binds Jak3 and leads to the activation of STAT (signal transducer and activator of transcription). Interestingly, the binding sites for TRAF6 and Jak3 overlap, whereas other members of the TRAF family bind to a distinct site (Ishida et al. 1996b; Hanissian and Geha 1997).

The importance of TRAF molecules for the growthpromoting effect of CD40 in B Iymphocytes is supported by studies with the Epstein-Barr virus (EBV) protein LMP1. LMP1 is essential for the transformation of primary B Iymphocytes by the virus (Izumi et al. 1997). The carboxy-terminal cytoplasmic domain of LM P1 has been 
shown to interact with TRAF proteins. Furthermore, recruitment of TRAFs by LMP1 has been demonstrated to be essential for the transforming capabilities of LMP1 and to play a role in the pathogenesis of EBV-positive Iymphomas in immunosuppressed patients (Kaye et al. 1996; Izumi et al. 1997; Liebowitz 1998).

Finally, two TRAF-associated TNFR-related proteins, 4-1BB and $O \times 40$, have been reported to function sol ely as triggers of survival pathways that lead to the up-regulation of NF-kB- and AP-1-regulated proteins and, subsequently, proliferation (Arch and Thompson 1998; Jang et al. 1998; Kawamata et al. 1998; Saoulli et al. 1998). Both molecules have been shown to be costimulatory molecules that lead to the augmentation of $\mathrm{T}$-cell proliferation after cross-linking of the $\mathrm{T}$-cell receptor (Godfrey et al. 1994; Hurtado et al. 1995, 1997; DeBenedette et al. 1997; Shuford et al. 1997). However, these receptors have not been studied as extensively as CD30 and CD40. They may ultimately al so facilitate cell death under certain circumstances.

Although some of the TRAFs, in particular TRAF2 and TRAF5, activate N F-кB and AP-1, other members of this adapter protein family such as TRAF3 have been reported to have negative effects on the activation of these transcription factors (Rothe et al. 1995b; Arch and Thompson 1998). The differential recruitment of activating or inhibitory TRAF molecules seems to be one level of regulation of receptor-induced signal transduction. The fact that the TRAF binding sites of the receptors differ substantially in sequence argues for differences in binding affinities of TRAF molecules for distinct receptor proteins. In addition, the possibility of homo- and/or heterodimerization of TRAF molecules that leads to the formation of higher order complexes could add another level of regulation. It is likely that differences in expression levels of TRAFs and/or depletion of distinct TRAF molecules after receptor recruitment and the nature of the multimerized receptor that recruits TRAFs will result in the formation of distinct multiprotein aggregates that will differentially modulate the downstream events that can keep cells alive or trigger apoptosis (Duckett and Thompson 1998).

\section{TRAF proteins may regulate a cell survival checkpoint}

Transfection experiments as well as transgenic and knockout animals have given insight into the function of TRAF proteins as mediators of life and death. The use of dominant-negative forms of TRAF molecules that still bind distinct receptors but do not initiate downstream signaling cascades was a first step toward the understanding of the role of TRA Fs as one of the key regulators of cellular stress responses. As described above, TRAF2, TRAF5, and TRAF6 appear to be inducers of positive signals for cell growth and proliferation that are mediated by kinase cascades and the induction of N F-kB- and AP-1-regulated genes. When these molecules are abundant, TNFR activation appears to promote a stress response. In contrast, in cells where these factors are depleted or inhibited by transdominant inhibitors an apop- totic response is favored (Duckett and Thompson 1998). Thus, TRAF protein availability and function may regulate a cell survival checkpoint involving either a stress response on the one side or programmed cell death on the other.

To date, TRAF2 is the most extensi vely studied TRAF, yet much more needs to be learned concerning its function. Although overexpression of a dominant-negative mutant of TRAF2 that lacks the amino-terminal RIN G finger domain (TRAF2DN) in vitro was found to inhibit NF-kB activation, expression of this mutant in vivo did not affect TNF-mediated NF-kB activation in thymocytes (Lee et al. 1997a). In contrast, JNK activation was severely impaired in thymocytes from these transgenic animals. Similar observations were made in TRAF2 ${ }^{-1-}$ mice (Yeh et al. 1997). Fibrobl asts from TRAF2 null mice were deficient in their ability to activate JN $\mathrm{K}$ in response to TNF- $\alpha$ treatment. However, these cells were essentially normal in their ability to activate NF-kB in response to TNF- $\alpha$. These data argue that TRAF2 plays a major role in activation of the JNK pathway via TN FRs. Although experiments in tissue culture systems argue that TRAF2 can regulate NF- $\mathrm{B}$ activation, the generation of TRAF2 ${ }^{-1-}$ mice and animals with a dominantnegative TRAF2 as a transgene demonstrated that TRAF2-independent pathways also exist.

Experiments using cells from TRAF2DN transgenic mice and TRAF2 null mice suggest that TRAF2 also has an antiapoptotic function. In vitro proliferation of thymocytes expressing TRAF2DN triggered by stimulation with an anti-TCR antibody immobilized to plastic was significantly reduced. Furthermore, cell death of TRAF2DN or TRAF2 ${ }^{-1-}$ thymocytes and activated Tcells induced by TNF- $\alpha$ or TNF- $\alpha$ and cycloheximide was increased. Study of TRAF2-deficient cells has confirmed the antiapoptotic function of TRAF2 and its importance for TNF-induced JNK activation ( $Y$ eh et al. 1997). TRAF2 ${ }^{-1-}$ animals appeared normal at birth, but the body weight was reduced significantly compared to control littermates and the knockout animals became runted and died prematurely within 3 weeks. With the exception of thymus and spleen, all organs appeared normal but had reduced sizes. The lymphoid organs were extremely atrophic, revealed ongoing lymphoid depletion and lack of secondary germinal centers. Interestingly, overexpression of the TRAF2DN transgene led to splenomegaly and Iymphadenopathy. Thus, although TRAF2 has a clear antiapoptotic function, it may also link TNFR family members to proapoptotic pathways.

In contrast to TRAF2, TRAF3 can have an inhibitory effect on N F-кB activation and was shown to be involved in the induction of cell death by the lymphotoxin- $\beta$ receptor (LT- $\beta$ R; VanArsdale et al. 1997). A mino-terminal deletion mutants of TRAF3 that interfere with the recruitment of endogenous TRAF3 to this receptor have a dominant-negative effect on cell death induced by LT - $\beta$ but have no influence on TN F- $\alpha$-triggered apoptosis (Force et al. 1997). Null mutations of TRAF3 in mice demonstrate the role of TRAF3 in T-dependent immune responses (Xu et al. 1996). All Iymphoid organs of 
TRAF3 $^{-1-}$ mice were significantly smaller than in those of littermate controls. Although the numbers of Iymphoid cells were only $\sim 1 \%$ of those of normal littermates neither thymocytes nor bone marrow cells from $\mathrm{TRAF}^{-1-}$ mice showed changes in the relative percentages of lymphocyte subpopulations. B cells from TRAF3 $^{-1-}$ mice showed no differences in proliferation upon stimulation with anti-IgM in vitro, but reconstitution experiments with TRA F3 ${ }^{-1-}$ fetal liver cells revealed defects in $\mathrm{T}$-dependent immune responses. $\mathrm{Y}$ et, $\mathrm{T}$ cells isolated from TRAF3-deficient mice had intrinsic defects and were impaired in their ability to respond to antigen. Therefore, TRAF3 appears to be important in signaling cascades that promote the activation and survival of $T$ cells. Interestingly, the knockout of TRAF3 al so leads to severely reduced glucose levels that correlate with a runted phenotype. The physiological cause of this phenomenon is unclear.

In summary, members of the TRAF family are multifunctional adapter proteins that are involved in intracelIular signaling pathways that regulate cell survival. In addition, TRAFs have been shown to interact with proteins that regul ate receptor-induced apoptosis, including TRADD, C-IAPs, and RIP. Thus, TRAF-mediated signals may directly induce survival, or TRAF interaction with intracellular proteins that trigger programmed cell death may interfere with the ability of the latter set of molecules to induce programmed cell death. Determination of affinities of distinct receptors for individual TRAF molecules and detailed mol ecular characterization of the components of TRAF signaling complexes will be necessary to unravel the essential functions of TRAFs in intracellular signal transduction cascades.

\section{Acknowledgments}

We thank Emma Masteller for hel pful comments on the manuscript.

\section{References}

Aizawa, S., H. N akano, T. Ishida, R. Horie, M. N agai, K. Ito, H. Yagita, K. Okumura, J. Inoue, and T. Watanabe. 1997. Tumor necrosis factor receptor-associated factor (TRAF) 5 and TRAF2 are involved in CD30-mediated NFKB activation. J. Biol. Chem. 272: 2042-2045.

Akiba, H., H. Nakano, S. Nishinaka, M. Shindo, T. Kobata, M. Atsuta, C. Morimoto, C.F. Ware, N.L. Malinin, D. Wallach, H. Yagita, and K. Okumura. 1998. CD27, a member of the tumor necrosis factor receptor superfamily, activates N F-кB and stress-activated protein kinase/c-Jun $\mathrm{N}$-terminal kinase via TRAF2, TRAF5, and NF-kB -inducing kinase. J. Biol. Chem. 273: 13353-13358.

Arch, R.H. and C.B. Thompson. 1998. 4-1BB and Ox40 are members of a tumor necrosis factor (TNF)-nerve growth factor receptor subfamily that bind TNF receptor-associated factors and activate nuclear factor $\kappa \mathrm{B}$. Mol. Cell. Biol. 18: 558565.

Baker, S.J. and E.P. Reddy. 1996. Transducers of life and death: TNF receptor superfamily and associated proteins. Oncogene 12: 1-9.
Bal dwin, A.S.J. 1996. The N F-кB and IкB proteins: N ew discoveries and insights. Ann. Rev. Immunol. 14: 649-681.

Beg, A.A. and D. Baltimore. 1996. An essential role for N F-kB in preventing TN F- $\alpha$-induced cell death. Science 274: 782-784.

Bellon, S.F., K.K. Rodgers, D.G. Schatz, J.E. Coleman, and T.A. Steitz. 1997. Crystal structure of the RAG1 dimerization domain reveals multiple zinc-binding motifs including a novel zinc binuclear cluster. Nat. Struct. Biol. 4: 586-591.

Bodmer J.-L., K. Burns, P. Schnei der, K. Hofmann, V. Steiner, M. Thome, T. Bornand, M. Hahne, M. Schröter, K. Becker, A. Wilson, L.E. French, J.L. Browning, H.R. MacDonald, and J. Tschopp. 1997. TRAM P, a novel apoptosis-mediating receptor with sequence homology to tumor necrosis factor receptor 1 and Fas (A po-1/CD95). Immunity 6: 79-88.

Borden, K.L.B. and P.S. Freemont. 1996. The RING finger domain: A recent example of a sequence-structure family. Curr. Opin. Struct. Biol. 6: 395-401.

Borden, K.L.B., M.N. Boddy, J. Lally, N .J. O'Reilly, S. Martin, K. Howe, E. Solomon, and P.S. Freemont. 1995. The solution structure of the RIN G finger domain from the acute promyelocytic leukaemia proto-oncoprotein PML. EMBO J. 14: 1532-1521.

Boucher, L.-M ., L.E.M. M arengère, Y. Lu, S. Thukral, and T.W. Mak. 1997. Binding sites of cytoplasmic effectors TRAF1, 2, and 3 on CD30 and other members of the TNF receptor superfamily. Biochem. Biophys. Res. Comm. 233: 592-600.

Brink, R. and H.F. Lodish. 1998. Tumor necrosis factor receptor (T N FR)-associated factor 2A (TRAF2A), a TRAF2 splice variant with an extended RING finger domain that inhibits TN FR2-mediated N F-кB. J. Biol. Chem. 273: 4129-4134.

Brodeur, S.R., G. Cheng, D. Baltimore, and D.A. Thorley-Lawson. 1997. Localization of the major N F-кB-activating site and the sole TRAF3 binding site of LMP-1 defines two distinct signaling motifs. J. Biol. Chem. 272: 19777-19784.

Cao, Z., J. Xiong, M. Takeuchi, T. Kurama, and D.V. Goeddel. 1996. TRAF6 is a signal transducer for interleukin-1. Nature 383: 443-446.

Cheng, G. and D. Baltimore. 1996. TAN K, a co-inducer with TRAF2 of TNF- and CD40L-mediated NF-kB activation. Genes \& Dev. 10: 963-973.

Cheng, G., A.M. Cleary, Z.-S. Ye, D.I. Hong, S. Lederman, and D. Baltimore. 1995. Involvement of CRAF1, a relative of TRAF, in CD40 signaling. Science 267: 1494-1498.

Chinnaiyan, A.M., K. O'Rourke, M. Tewari, and V.M. Dixit. 1995. FADD, a novel death domain containing protein, interacts with the death domain of Fas and initiates apoptosis. Cell 81: $505-512$.

Chinnaiyan, A.M., K. O'Rourke, G.-L. Yu, R.H. Lyons, M. Garg, D.R. Duan, L. Xing, R. Gentz, J. Ni, and V.M. Dixit. 1996. Signal transduction by DR3, a death domain containing receptor related to TNFR-1 and CD95. Science 274: 990-992.

Clement, M.-V. and I. Stamenkovic. 1994. Fas and tumor necrosis factor receptor-mediated cell death: Similarities and distinctions. J. Exp. Med. 180: 557-567.

Cleveland, J.L. and J.N. Ihle.1995. Contenders in FasL/TNF death signaling. Cell 81: 479-482.

DeBenedette, M.A., A. Shahinian, T.W. Mak, and T.H. Watts. 1997. Costimulation of CD28- $\mathrm{T}$ Iymphocytes by $4-1 \mathrm{BB}$ ligand. J. Immunol. 158: 551-559.

Devergne, O., E. Hatzivassiliou, K.M. Izumi, K.M. Kaye, M.F. Kleijnen, E. Kieff, and G. Mosialos. 1996. Association of TRAF1, TRAF2, and TRAF3 with an Epstein-Barr virus LMP1 domain important for B-lymphocyte transformation: Role in N F-кB activation. Mol. Cell. Biol. 16: 7098-7108.

DiDonato, J.A., M. Hayakawa, D.M. Rothwarf, E. Zandi, and M. Karin. 1997. A cytokine-responsive $І_{\kappa} B$ kinase that activates 
the transcription factor NF-кB. N ature 388: 548-554.

Duckett, C.S. and C.B. Thompson. 1998. CD30-dependent degradation of TRAF2: Implications for negative regulation of TRAF signaling and the control of cell survival. Genes \& Dev. 11: 2810-2821.

Duckett, C.S., R.W. Gedrich, M.C. Gilfillan, and C.B. Thompson. 1997. Induction of nuclear factor $\kappa B$ by the $C D 30$ receptor is mediated by TRAF1 and TRAF2. Mol. Cell. Biol. 17: 1535-1542.

Force, W.R., T.C. Cheung, and C.F. Ware. 1997. Dominant negative mutants of TRAF3 reveal an important role for the coiled coil domains in cell death signaling by the lymphotoxin- $\beta$ receptor. J. Biol. Chem. 272: 30835-30840.

Gedrich, R.W., M.C. Gilfillan, C.S. Duckett, J.L. Van Dongen, and C.B. Thompson. 1996. CD30 contains two binding sites with different specificities for members of the tumor necrosis factor receptor-associated factor family of signal transducing proteins. J. Biol. Chem. 271: 12852-12858.

Godfrey, W.R., F.F. Fagnoni, M.A. Harara, D. Buck, and E.G. Engleman. 1994. Identification of a human OX-40 ligand, a costimulator of $C D 4^{+} \mathrm{T}$ cells with homology to tumor necrosis factor. J. Exp. Med. 180: 757-762.

Griffith, T.S., X. Yu, J.M. Herndon, D.R. Green, and T.A. Ferguson. 1996. CD95-induced apoptosis of Iymphocytes in an immune privileged site induces immunological tolerance. Immunity 5: 7-16.

Hanissian, S.H. and R.S. Geha. 1997. Jak3 is associated with CD40 and is critical for CD40 induction of gene expression in B cells. Immunity 6: 379-397.

Hibi, M., A. Lin, T. Smeal, A. Minden, and M. Karin. 1993. Identification of an oncoprotein- and UV-responsive protein kinase that binds and potentiates the c-Jun activation domain. Genes \& Dev. 7: 2135-2148.

Hsu, H., J. Xiong, and D.V. Goeddel. 1995. The TNF receptor 1-associated protein TRADD signals cell death and NF-кB activation. Cell 81: 495-504.

Hsu, H., H.-B. Shu, M.-G. Pan, and D.V. Goeddel. 1996. TRADD-TRAF2 and TRADD-FADD interactions define two distinct TNF receptor 1 signal transduction pathways. Cell 84: 299-308.

Hu, H.M., K. O'Rourke, M.S. Boguski, and V.M. Dixit. 1994. A novel RING finger protein interacts with the cytoplasmic domain of CD40. J. Biol. Chem. 269: 30069-30072.

Huang, B., M. Eberstadt, E.T. Olejniczak, R.P. M eadows, and S.W. Fesik. 1996. N M R structure and mutagenesis of the Fas (A po-1/CD95) death domain. Nature 384: 638-641.

Huang, S., Y. Jiang, Z. Li, E. Nishida, P. Mathias, S. Lin, R.J. Ulevitch, G.R. N emerow, and J. Han. 1997. A poptosis signaling pathway in T cells is composed of ICE/Ced-3 family proteases and MAP kinase kinase 6b. Immunity 6: 739-749.

Hurtado, J.C., S.H. Kim, K.E. Pollok, Z.H. Lee, and B. Kwon. 1995. Potential role of 4-1BB in T cell activation. Comparison with the costimulatory molecule CD28. J. Immunol. 155: 3360-3367.

Hurtado, J.C., Y.-J. Kim, and B. Kwon. 1997. Signals through 4-1BB are costimulatory to previously activated splenic T cells and inhibit activation-induced cell death. J. Immunol. 158: 2600-2609.

Inouye, C., N. Dhillon, and J. Thorner. 1997. Ste5 RING-H2 domain: Role in Ste4-promoted oligomerization for yeast pheromone signaling. Science 278: 103-106.

Ishida, T., T. Tojo, T. Aoki, N. Kobayashi, T. Ohishi, T. Watanabe, T. Yamamoto, and J.-I. Inoue. 1996a. TRAF5, a novel tumor necrosis factor receptor-associated factor family protein, mediates CD40 signaling. Proc. Natl. Acad. Sci. 93: 9437-9442.
Ishida, T., S.-i. Mizushima, S. Azuma, N. Kobayashi, S. Tojo, N. Kobayashi, T. Tojo, K. Suzuki, S. Aizawa, T. Watanabe, G. M osial os, E. Kieff, T. Y amamoto, and J.-I. Inoue. 1996b. Identification of TRAF6, a novel tumor necrosis factor receptorassociated factor protein that mediates signaling from an amino-terminal domain of the CD40 cytoplasmic region. J. Biol. Chem. 271: 28745-28748.

Itoh, N ., S. Y onehara, A. Ishii, M. Yonehara, S.-I. M izushima, M. Sameshima, A. Hase, Y. Setp, and S. N agata. 1991. The polypeptide encoded by the cDN A for human cell surface antigen Fas can mediate apoptosis. Cell 66: 233-243.

Izumi, K.M., K.M. Kaye, and E. Kieff. 1997. The Epstein-Barr virus LM P1 amino acid sequence that engages tumor necrosis factor receptor associated factors is critical for primary $B$ lymphocyte growth transformation. Proc. Natl. Acad. Sci. 94: 1447-1452.

Jang, I.K., Z.H. Lee, Y.J. Kim, S.H. Kim, and B.S. Kwon. 1998. Human 4-1BB (CD137) signals are mediated by TRAF2 and activate nuclear factor-кB. Biochem. Biophys. Res. Commun. 242: 613-620.

Kamanaka, M., P. Yu, T. Yasui, K. Yoshida, T. Kawabe, T. Horii, T. Kishimoto, and H. Kikutani. 1996. Protective role of CD40 in Leishmania major infection at two distinct phases of cell-mediated immunity. Immunity 4: 275-281.

Kawamata, S., T. Hori, A. Imura, A. Takaori-Kondo, and T. Uchiyama. 1998. Activation of OX40 signal transduction pathways leads to tumor necrosis factor receptor-associated factor (TRAF) 2- and TRAF5-mediated NF- $\mathrm{BB}$ activation. J. Biol. Chem. 273: 5808-5814.

Kaye, K.M., O. Devergne, J.N . Harada, K.M. Izumi, R. Zalamanchili, E. Ki eff, and G. Mosial os. 1996. Tumor necrosis factor receptor associated factor 2 is a mediator of N F-кB activation by latent infection membrane protein 1, the Epstein-Barr virus transforming protein. Proc. Natl. Acad. Sci. 93: 1108511090.

Kelliher, M.A., S. Grimm, Y. Ishida, F. Kuo, B.Z. Stanger, and P. Leder. 1998. The death domain kinase RIP mediates the TNF-induced N F-кB signal. Immunity 8: 297-303.

Kuhné, M.R., M. Robbins, J.E. Hambor, M.F. Mackey, Y. Kosaka, T. Nishimura, J.P. Gigley, R.J. N oelle, and D.M. Calderhead. 1997. Assembly and regulation of the CD40 receptor complex in human B Cells. J. Exp. Med. 186: 337-342.

Lee, S.Y., S.Y. Lee, G. Kandala, M.-L. Liou, H.-C. Liou, and Y. Choi. 1996a. CD30/TNF receptor-associated factor interaction: NF-кB activation and binding specificity. Proc. Natl. Acad. Sci. 93: 9699-9703.

Lee, S.Y., C.G. Park, and Y. Choi. 1996b. T cell receptor-dependent cell death of $T$ cell hybridomas mediated by the CD 30 cytoplasmic domain in association with tumor necrosis factor receptor-associated factors. J. Exp. Med. 183: 669-674.

Lee, S.Y., A. Reichlin, A. Santana, K.A. Sokol, M.C. N ussenzweig, and Y. Choi. 1997a. TRAF2 is essential for JNK but not NF-кB activation and regulates lymphocyte proliferation and survival. Immunity 7: 703-713.

Lee, S.Y., S.Y. Lee, and Y. Choi. 1997b. TRAF-interacting Protein (TRIP): A novel component of the tumor necrosis factor receptor (TNFR)- and CD30-TRAF signaling complex that inhibits TRAF2-mediated NF-kB activation. J. Exp. Med. 185: 1275-1285.

Liebowitz, D. 1998. Epstein-Barr virus and a cellular signaling pathway in Iymphomas from immunosuppressed patients. N. Eng. J. Med. 338: 1413-1421.

Lin, A., A. Minden, H. Martinetto, F.X. Claret, C. Lange-Carter, F. Mercurio, G.L. Johnson, and M. Karin. 1995. Identification of a dual specificity kinase that activates the Jun kinases and p38-M pk2. Science 268: 286-290. 
Liu, Z.-g., H. Hsu, D.V. Goeddel, and M. Karin. 1996. Dissection of TNF receptor 1 effector functions: JNK activation is not linked to apoptosis while NF-kB activation prevents cell death. Cell 87: 565-576.

Mackay, J.P. and M. Crossley. 1998. Zinc fingers are sticking together. Trends Biochem. Sci. 23: 1-4.

Malinin, N.L., M.P. Boldin, A.V. Kovalenko, and D. Wallach. 1997. M AP3K-related kinase involved in N F-кB induction by TNF, CD 95 and IL-1. Nature 385: 540-544.

Marsters, S.A., T.M. Ayres, M. Skubatch, C.L. Gray, M. Rothe, and A. Ashkenazi. 1997. Herpesvirus entry mediator, a member of the tumor necrosis factor receptor (TNFR) family, interacts with members of the TNFR-associated factor family and activates the transcription factors N F-кB and AP1. J. Biol. Chem. 273: 14029-14032.

Masson, R., C.H. Régnier, M.-P. Chenard, C. Wendling, M.-G. M attei, C. Tomasetto, and M.-C. Rio. 1998. Tumor necrosis factor receptor associated factor 4 (TRAF4) expression pattern during mouse development. Mech. Dev. 71: 187-191.

McCarthy, J.V., J. Ni, and V.M. Dixit. 1998. RIP2 is a novel NF-kB-activating and cell death-inducing kinase. J. Biol. Chem. 273: 16968-16975.

Medzhitov, R., P. Preston-Hurlburt, and C.A. Janeway. 1997. A human homologue of the Drosophila Toll protein signals activation of adaptive immunity. N ature 388: 394-397.

Medzhitov, R.M., P. Preston-Hurlburt, E. Kopp, A. Stadlen, C. Chen, S. Gosh, and C.A. Janeway. 1998. M yD 88 is an adapter protein in the hToll/IL-1 receptor family signaling pathways. Mol. Cell (in press).

Minden, A., A. Lin, M. M CM ahon, C. Lange-Carter, B. Derijard, R.J. Davis, G.L. Johnson, and M. Karin. 1994. Differential activation of ERK and JNK mitogen-activated protein kinases by Raf-1 and MEKK. Science 266: 1719-1723.

Mosialos, G., M. Birkenbach, R. Yalamanchili, T. VanArsdale, C. Ware, and E. Kieff. 1995. The Epstein-Barr virus transforming protein LM P1 engages signaling proteins for the tumor necrosis factor receptor family. Cell 80: 389-399.

Muzio, M., A.M. Chinnaiyan, F.C. Kischkel, K. O'Rourke, A. Shevchenko, J. Ni, C. Scaffidi, J.D. Bretz, M. Zhang, R. Gentz, M. Mann, P.H. Krammer, M.E. Peter, and V.M. Dixit. 1996. FLICE, a novel FADD-homologous ICE/CED-3-like protease, is recruited to the CD95 (Fas/APO-1) death-inducing signaling complex. Cell 85: 817-827.

N agata, S. 1997. A poptosis by death factor. Cell 88: 355-365.

Nakano, H., H. Oshima, W. Chung, L. Williams-Abbott, C.F. Ware, H. Yagita, and K. Okumura. 1996. TRAF5, an activator of NF-кB and putative signal transducer for the lymphotoxin- $\beta$ receptor. J. Biol. Chem. 271: 14661-14664.

N oelle, R.J. 1996. CD40 and its ligand in host defense. Immunity 4: 415-419.

Opipari, A.W., H.M. Hu, R. Yabkowitz, and V.M. Dixit. 1992. The A20 zinc finger protein protects cells from tumor necrosis factor cytotoxicity. J. Biol. Chem. 267: 12424-12427.

Régnier, C.H., C. Tomasetto, C. Moog-Lutz, M.-P. Chenard, C. Wendling, P. Basset, and M.-C. Rio. 1995. Presence of a new conserved domain in CART1, a novel member of the tumor necrosis factor receptor-associated protein family, which is expressed in breast carcinoma. J. Biol. Chem. 270: 2571525721.

Régnier, C.H., H.Y. Song, X. Gao, D.V. Goeddel, Z. Cao, and M. Rothe. 1997. Identification and characterization of an $I_{\kappa} B$ kinase. Cell 90: 373-383.

Reinhard, C., B. Shamoon, V. Shyamala, and L.T. Williams. 1997. Tumor necrosis factor $\alpha$-induced activation of c-jun $\mathrm{N}$-terminal kinase is mediated by TRAF2. EMBO J. 16: 1080-1092.
Rothe, M., S.C. Wong, W.J. Henzel, and D.V. Goeddel. 1994. A novel family of putative signal transducers associated with the cytoplasmic domain of the $75 \mathrm{kD}$ a tumor necrosis factor receptor. Cell 78: 681-692.

Rothe, M., M.-G. Pan, W.J. Henzel, T.M. Ayres, and D.V. Goeddel. 1995a. The TNFR2-TRAF signaling complex contains two novel proteins related to baculoviral inhibitor of apoptosis proteins. Cell 83: 1243-1252.

Rothe, M., V. Sarma, V.M. Dixit, and D.V. Goeddel. 1995b. TRAF2-mediated activation of N F-кB by TN F receptor 2 and CD40. Science 269: 1424-1427.

Rothe, M., J. Xiong, H.-B. Shu, K. Williamson, A. Goddard, and D.V. Goeddel. 1996. I-TRAF is a novel TRAF-interacting protein that regulates TRAF-mediated signal transduction. Proc. Natl. Acad. Sci. 93: 8241-8246.

Roy, N., Q.L. Deveraux, R. Takahashi, G.S. Salvesen, and J.C. Reed. 1997. The C-IAP-1 and C-IAP-2 proteins are direct inhibitors of specific caspases. EMBO J. 16: 6914-6925.

Saitoh, M., H. Nishitoh, M. Fujii, K. Takeda, K. Tobiume, Y. Sawada, M. Kawabata, K. Miyazono, and H. Ichijo. 1998. Mammalian thioredoxin is a direct inhibitor of apoptosis signal-regulating kinase (ASK) 1. EMBO J. 17: 2596-2606.

Sandberg, M., W. Hammerschmidt, and B. Sugden. 1997. Characterization of LMP-1's association with TRAF1, TRAF2, and TRAF3. J. Virol. 71: 4649-4656.

Saoulli, K., S.Y. Lee, J.L. Cannons, W.C. Yeh, A. Santana, M.D. Goldstein, N. Bangia, M.A. DeBenedette, T.W. Mak, Y. Choi, and T.H. Watts. 1998. CD28-independent, TRAF2-dependent costimulation of resting $T$ cells by 4-1BB ligand. J. Exp. Med. 187: 1849-1862.

Sato, T., S. Irie, and J.C. Reed. 1995. A novel member of the TRAF family of putative signal transducing proteins binds to the cytosolic domain of CD40. FEBS Lett. 358: 113-118.

Shi, C.-S. and J.H. Kehrl. 1997. Activation of stress-activated protein kinase/c-Jun $\mathrm{N}$-terminal kinase, but not NF-kB, by the tumor necrosis factor (TNF) receptor 1 through a TNF receptor-associated factor 2 - and germinal center kinase related-dependent pathway. J. Biol. Chem. 272: 32102-32107.

Shuford, W.W., K. Klussman, D.D. Tritchler, D.T. Loo, J. Chalupny, A.W. Siadak, T.J. Brown, J. Emswiler, H. Raecho, C.P. Larsen, T.C. Pearson, J.A. Ledbetter, A. A ruffo, and R.S. Mittler. 1997. 4-1BB costimulatory signals preferentially induce CD8+ $T$ cell proliferation and lead to the amplification in vivo of cytotoxic T cell responses. J. Exp. Med. 186: 47-55.

Smith, C.A., T. Farrah, and R.G. Goodwin. 1994. The TNF receptor superfamily of cellular and viral proteins: Activation, costimulation, and death. Cell 76: 959-962.

Song, H.Y., M. Rothe, and D.V. Goeddel. 1996. The tumor necrosis factor-inducible zinc finger protein A20 interacts with TRAF1/TRAF2 and inhibits NF-кB activation. Proc. Natl. Acad. Sci. 93: 6721-6725.

Song, H.Y., C.H. Régnier, C.J. Kirschning, D.V. Goeddel, and M. Rothe. 1997. Tumor necrosis factor (TNF)-mediated kinase cascades: Bifurcation of nuclear factor- $\mathrm{kB}$ and c-jun $\mathrm{N}$-terminal kinase (JNK/SAPK) pathways at TN F receptor-associated factor 2. Proc. Natl. Acad. Sci. 94: 9792-9796.

Soong, L., J.-C. Xu, I.S. Grewal, P. Kima, J. Sun, B.J. Longley, N.H. Ruddle, D. McM ahon-Pratt, and R.A. Flavell. 1996. Disruption of CD40-CD 40 ligand interactions results in an enhanced susceptibility to Leishmania amazonensis infection. Immunity 4: 263-273.

Speiser, D.E., S.Y. Lee, B. Wong, J. Arron, A. Santana, Y.-Y. Kong, P.S. Ohashi, and Y. Choi. 1997. A regulatory role for TRAF1 in antigen-induced apoptosis of T cells. J. Exp. Med. 185: 1777-1783.

Stanger, B.Z., P. Leder, T.-H. Lee, E. Kim, and B. Seed. 1995. RIP: 


\section{Arch et al.}

A novel protein containing a death domain that interacts with Fas/APO-1 (CD95) in yeast and causes cell death. Cell 81: 513-523.

Su, B., E. Jacinto, M. Hibi, T. Kallunki, M. Karin, and Y. BenNeriah. 1994. JNK is involved in signal integration during costimulation of T lymphocytes. Cell 77: 727-736.

Takeuchi, M., M. Rothe, and D.V. Goeddel. 1996. Anatomy of TRAF2. Distinct domains for nuclear factor- $\mathrm{B}$ activation and association with tumor necrosis factor signaling proteins. J. Biol. Chem. 271: 19935-19942.

Tartaglia, L.A., M. Rothe, Y.-F. Hu, and D.V. Goeddel. 1993. Tumor necrosis factor's cytotoxic activity is signal ed by the p55 TN F receptor. Cell 73: 213-216.

Ting, A.T., F.X. Pimentel-Muiños, and B. Seed. 1996. RIP mediates tumor necrosis factor receptor 1 activation of N F-KB but not Fas/APO-1-initiated apoptosis. EMBO J. 15: 61896196.

Uren, A.G., M. Pakusch, C.J. Hawkins, K.L. Puls, and D.L. Vaux. 1996. Cloning and expression of apoptosis inhibitory protein homologs that function to inhibit apoptosis and/or bind tumor necrosis factor receptor-associated factors. Proc. Natl. Acad. Sci. 93: 4974-4978.

Van Antwerp, D.J., S.J. Martin, T. Kafri, D.R. Green, and I.M. Verma. 1996. Suppression of TNF- $\alpha$-induced apoptosis by N F-кB. Science 274: 787-789.

VanArsdale, T.L., S.L. VanArsdale, W.R. Force, B.N. Walter, G. Mosialos, E. Kieff, J.C. Reed, C.F. Ware. 1997. Lymphotoxin- $\beta$ receptor signaling complex: Role of tumor necrosis factor receptor-associated factor 3 recruitment in cell death and activation of nuclear factor $\kappa$ B. Proc. Natl. Acad. Sci. 94: 2460-2465.

Van Parijs, L.A. Ibraghimov, and A.K. A bbas. 1996. The roles of costimulation and Fas in T cell apoptosis and peripheral tolerance. Immunity 4: 321-328.

Verma, I.M. and J. Stevenson. 1997. IкB kinase: Beginning, not the end. Proc. Natl. Acad. Sci. 94: 11758-11760.

Wang, C.-Y., M.W. Mayo, and A.S. Baldwin. 1996. TNF- and cancer therapy-induced apoptosis: Potentiation by inhibition of N F-кB. Science 274: 784-787.

Xu, Y., G. Cheng, and D. Baltimore. 1996. Targeted disruption of TRAF3 leads to postnatal lethal ity and defective T-dependent immune responses. Immunity 5: 407-415.

Yeh, W.-C., A. Shahinian, D. Speiser, J. Kraunus, F. Billia, A. Wakeham, J.L. de la Pompa, D. Ferrick, B. Hum, N. Iscove, P. Ohashi, M. Rothe, D.V. Goeddel, and T.W. Mak. 1997. Early lethality, functional NF-kB activation and increased sensitivity to TNF-induced cell death in TRAF2-deficient mice. Immunity 7: 715-725.

Zandi, E., D.M. Rothwarf, M. Delhase, M. Hayakawa, and M. Karin. 1997. The $I_{\kappa} B$ kinase complex (IKK) contains two kinase subunits, IKK $\alpha$ and IKK $\beta$, necessary for $I_{K} B$ phosphorylation and NF-kB activation. Cell 91: 243-252. 


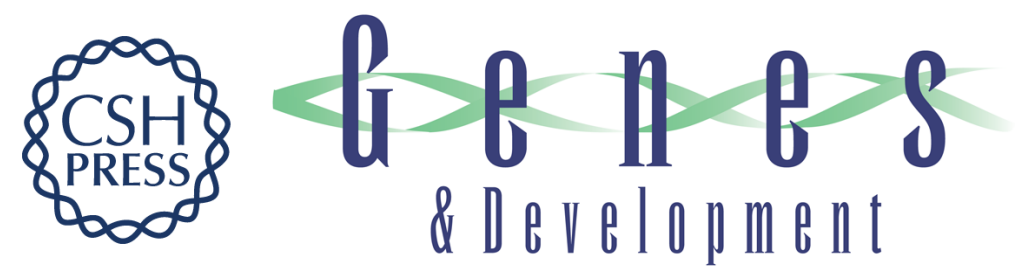

\section{Tumor necrosis factor receptor-associated factors (TRAFs)--a family of adapter proteins that regulates life and death}

Robert H. Arch, Richard W. Gedrich and Craig B. Thompson

Genes Dev. 1998, 12:

Access the most recent version at doi:10.1101/gad.12.18.2821

References This article cites 101 articles, 54 of which can be accessed free at: http://genesdev.cshlp.org/content/12/18/2821.full.html\#ref-list-1

License

Email Alerting

Receive free email alerts when new articles cite this article - sign up in the box at the top Service right corner of the article or click here.

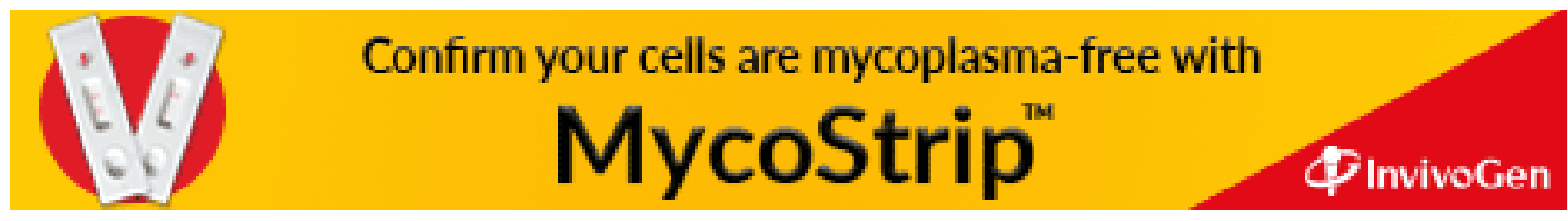

